\title{
Minireview
}

\section{The use of radiofrequency in cancer}

\author{
AR Gillams*,I \\ 'Department of Medical Imaging, The Middlesex Hospital, Mortimer Street, London WIT 3AA, UK
}

Radiofrequency ablation (RFA) provides an effective technique for minimally invasive tissue destruction. An alternating current delivered via a needle electrode causes localised ionic agitation and frictional heating of the tissue around the needle. Image-guided, percutaneous ablation techniques have been developed in most parts of the body, but the most widely accepted applications are for the treatment of hepatocellular carcinoma (HCC) in early cirrhosis, limited but inoperable colorectal liver metastases, inoperable renal cell carcinoma and inoperable primary or secondary lung tumours. The procedures are well tolerated and the complication rates low. Patients with coexistent morbidity who are not suitable for surgery are often able to undergo RFA. Most treatments in the lung, kidney and for HCC are performed under conscious sedation with an overnight hospital stay or as a day-case. Larger more complicated ablations, for example, in hepatic metastases may require general anaesthesia. Limitations of RFA include the volume of tissue that can be ablated in a timely fashion, that is, most centres will treat 3-5 tumours up to $4-5 \mathrm{cms}$ in diameter. Early series reporting technical success and complications are available for lung and renal ablation. Liver ablation is better established and 5-year survival figures are available from several centres. In patients with limited but inoperable colorectal metastases, the 5-year survival ranges from 26 to $30 \%$ and for HCC it is just under $50 \%$. In summary, RFA provides the opportunity for localised tissue destruction of limited volumes of tumour; it can be offered to nonsurgical candidates and used in conjunction with systemic therapy.

British Journal of Cancer (2005) 92, I825-1829. doi:I0.1038/sj.bjc.6602582 www.bjcancer.com

Published online 3 May 2005

(c) 2005 Cancer Research UK

Keywords: thermal ablation; radiofrequency; hepatocellular carcinoma; liver metastases; inoperable pulmonary malignancy; renal cell carcinoma

Image guided ablation dates to 1989 when the first US guided interstitial laser treatments were performed in liver metastases and the first percutaneous ethanol injections were reported for the treatment of small hepatocellular carcinoma (HCC). Rapid technological developments have resulted in the development of a number of ablative techniques, higher power generators and a range of different electrode designs. Current designs permit ablation of much larger volumes of tissue than was originally possible. Radiofrequency ablation (RFA) has been used in a wide range of locations and applications including adrenal metastases, primary colorectal cancer recurrence and malignant pelvic or paraaortic lymphadenopathy (Lees and Gillams, 2005), but in this article we will consider the main areas where RFA has proven effective or is likely to do so.

\section{TECHNICAL FEATURES}

Radiofrequency ablation uses needle electrodes to deliver an alternating current that generates ionic agitation, localised frictional tissue heating and cell death. A range of electrode designs is available ranging in caliber from 14 to $17 \mathrm{G}$. Most are designed to be inserted percutaneously using image guidance. Various design features have been put forward (water cooling, saline perfusion, monopolar or bipolar, coil or expandable

*Correspondence: Dr A Gillams; E-mail: a.gillams@medphys.ucl.ac.uk Received I 8 February 2005; accepted I 8 March 2005; published online 3 May 2005 designs), all aimed at increasing the volume of confluent necrosis that can be achieved per unit time. Ultrasound (US) is the preferred technique for electrode placement but where US is not possible, for example, in lung ablation or in US occult liver tumours, then CT or MR are used. Assessment of the efficacy of ablation is achieved using contrast-enhanced CT or MR. Absent enhancement denotes the area of necrosis. Thermal techniques result in coagulation necrosis and an instantaneous thermal fixation' effect. Tissue architecture is preserved, routine histological stains are misleading and enzymatic assays are required to establish tissue nonviability ( $\mathrm{Ni}$ et al, 2005).

\section{LIVER METASTASES}

\section{Colorectal}

This patient population represents one of the most common indications for RFA in the UK. Liver resection is currently considered the first line of treatment for those with surgical disease, but there are many patients who are not suitable for resection either because of comorbidity, tumour location or inadequate hepatic reserve (most commonly in patients who have undergone a previous resection). These patients may well benefit from RFA to the liver either in isolation or in conjunction with systemic chemotherapy. As liver metastases usually arise in an otherwise normal liver, the extent of disease that can be safely treated is greater than for patients with HCC arising on a 
background of cirrhosis. Most centres will accept patients with as many as five tumours, maximum diameter $5 \mathrm{~cm}$. We have published our survival results in 167 patients with colorectal metastases treated with RFA but have now treated over 215 patients (Gillams and Lees, 2004). A total of 96 patients conformed to the above criteria and their survival was a median, 1,3 and 5 years from the diagnosis of liver metastases of 38 months, 99, 59 and $29 \%$ and from the time of first thermal ablation was 31 months, 89,33 and $20 \%$. Other groups have reported similar survival results and the Milan group reported their results in 117 patients with up to four metastases, mean diameter $2.8 \mathrm{~cm}$. The vast majority (103 out of $117(88 \%)$ ) of their patients had either one or two tumors. The median survival in this cohort, who had more limited disease than our cohort, was 36 months and their 3year survival was $46 \%$ (Solbiati et al, 2001). Vogl et al (2004) have reported a similar median survival of 35 months in patients with five tumours or less, maximum diameter $5 \mathrm{~cm}$. This group uses a different thermal technique (neodymium yttrium aluminium garnet (NdYAG) laser ablation) and a combination of CT guidance for applicator placement and high field MR monitoring of the thermal effect.

Analysis of patients with small solitary lesions, that is, surgical disease but in those who were not suitable for surgery, reveals even better survival figures. In our cohort, 34 patients had small solitary tumours with a median diameter of $2.5 \mathrm{~cm}$, the mean and 3-year survival from ablation was 67 months and 66\%, respectively. Two retrospective comparisons between surgery and RFA suggest comparable survival between the two modalities (Elias et al, 2002; Oshowo et al, 2003); however, no prospective studies are underway. A different approach is to use RFA as a 'test of time' this has been explored by the Milan group who have offered RFA to surgical candidates (Livraghi et al, 2003a). Those who do not develop further disease are spared a resection, those who develop more extensive disease such that they are no longer operable on short-term follow-up are spared an un-necessary and ineffective surgical resection and those that recur can undergo resection. In their cohort of 88 patients, $60 \%$ achieved complete ablation and did not require resection. An on-going trial, sponsored by The European Organisation for Research and Treatment of Cancer (EORTC), is looking at a different patient population, those with inoperable colorectal liver metastases. This trial aims to compare the effect of ablation in conjunction with systemic chemotherapy with systemic chemotherapy alone, that is, Chemotherapy + Local ablation vs Chemotherapy (CLOCC) trial. The acceptance criteria are more generous than traditional acceptance criteria. Patients can have as many as nine metastases with a maximum diameter of $4 \mathrm{~cm}$. We have retrospectively analysed our data according to the CLOCC acceptance criteria. A theoretical projection comparing our results with published Oxaliplatin and 5 fluorouracil (5FU) data is shown in Figure 1 (Giacchetti et al, 2000). This projection would suggest a useful survival advantage for the addition of ablation to systemic chemotherapy but only the on-going prospective study will provide the required evidence.

Complication rates of RFA are low with a mortality of $<0.8 \%$ and morbidity of $5-10 \%$. Collateral damage can largely be avoided by isolating the liver from adjacent vulnerable structures, for example, colon or duodenum. This is usually readily achievable by the instillation of $<11$ of $5 \%$ dextrose through a $19 \mathrm{G}$ spinal needle positioned between the ablation area and the vulnerable viscus. Major bile ducts are susceptible to thermal injury and need to be cooled. Bleeding is uncommon in patients with normal coagulation and a normal liver parenchyma. Although one centre has reported very high rates of tumour seeding following biopsy and RFA (Llovet et al, 2001), in all other centres tumour seeding is exceptional $-0.5 \%$ in one multicentre study which included 41 centres and over 2000 patients (Livraghi et al, 2003b). Secondary infection of an ablation zone can occur, usually as a late complication. Patients with bilio-enteric anastomoses or biliary

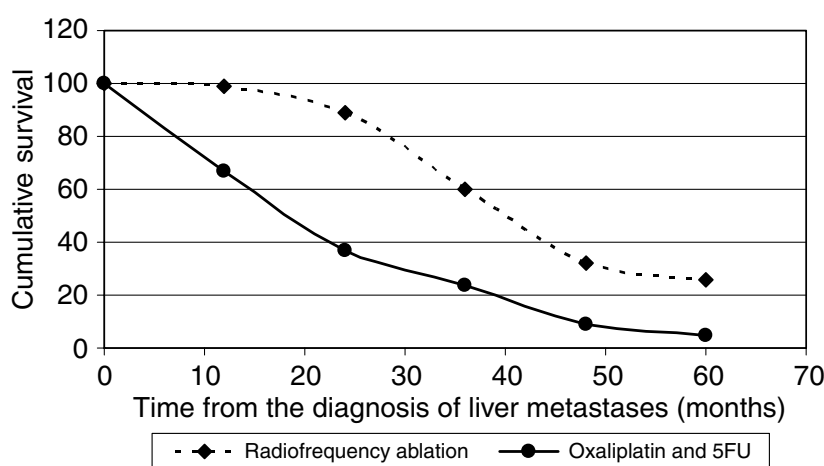

Figure I A theoretical projection of survival following RFA (in patients with CLOCC acceptance criteria from our database) vs published Oxaliplatin and 5FU chemotherapy results.

stents are particularly likely to develop secondary infection presumably due to reflux of intestinal organisms into the biliary tree and therefore these patients should receive 3 months of rotating oral antibiotics post-ablation.

\section{Breast}

The median survival for patients with metastatic breast cancer is 2 years; however, those with hepatic metastases have a worse prognosis. A small group of patients, 5-12\%, have metastases confined to the liver. Some centres offer hepatic resection in this group and reported 3-year survival rates are $35-71 \%$. The median survival of patients with secondary liver metastases following chemotherapy is 4.5 months; agents such as docetaxel may only improve survival to 9-14.7 months. Liver metastases tend to be resistant to hormonal manipulation, often being negative for hormone receptors. Liver resection is being considered more frequently but where resection is not possible RFA can be used for patients with limited liver metastases who either have no extrahepatic disease or who have stable, controlled extra-hepatic disease. We have follow-up on 19 patients treated with RFA, eight had disease confined to the liver, with 11 having stable extrahepatic disease in addition. Seven patients with disease confined to the liver at presentation are alive, as are six with extra-hepatic disease, median follow up after RFA was 15 months (range $0-77$ ). Survival at 30 months was five out of $12(41.6 \%)$, in addition seven followed up for a median of 14 months (range 2-29) remain alive and disease free. Livraghi et al treated 24 patients; 10 (41.6\%) were disease free at a median follow up of 10 months. Therefore, there does appear to be a subgroup of patients who may benefit from local ablative therapy.

\section{Neuroendocrine}

There are numerous treatment options for patients with neuroendocrine metastases, yet none is both widely applicable and effective in reducing tumour load. For many of these patients, the natural history of the disease whereby multiple often small metastases develop over a period of years renders them particularly suitable for a minimally invasive technique that can be repeated frequently while sacrificing the least amount of normal liver parenchyma. Radiofrequency ablation can be used to reduce hormone secretion and/or to control total tumour load. In our experience in 25 patients, we achieved local control of tumour volume in 14 out of 19 (74\%) patients. There was a complete response in six, partial response in seven and stable disease in one at a median follow-up of 21 months (range 4-75). Relief or a reduction in hormone-related symptoms was achieved in nine of 
$14(69 \%)$ with secreting tumours. The median survival from the diagnosis of liver metastases was 53 months (Gillams et al, 2005). Symptomatic carcinoid patients require peri-procedural IV Octreotide with careful monitoring during and after the procedure as ablation, like other interventional procedures, can result in hormone release and rapid changes in blood pressure.

\section{PRIMARY HEPATOCELLULAR CARCINOMA}

Percutaneous, image-guided ablation has been used in the treatment of limited HCC for many years. Originally, chemical methods were used with either acetic acid or $100 \%$ ethanol. Ethanol is still used but increasingly thermal techniques such as radiofrequency, interstitial laser coagulation and microwave are becoming the preferred techniques. The presence of background cirrhosis in the vast majority of patients with HCC reduces the attractiveness of liver resection. Chemotherapy is ineffective and only recently met-analyses have suggested that chemoembolisation has an impact on survival (Camma et al, 2002). To be suitable for a local ablative technique, patients should have one HCC nodule less than $5 \mathrm{~cm}$ or as many as three nodules $<3 \mathrm{~cm}$ in maximum diameter. The underlying liver disease should be no more advanced than Child Pugh class B. Retrospective comparisons of percutaneous ethanol injection (PEI) and resection show similar survival results (Livraghi et al, 1995). More recently, a prospective comparison of radiofrequency and PEI in 102 patients showed a significantly longer disease-free survival in the RFA group. The 1and 2-year local recurrence-free survival rates were 98 and $96 \%$ in the RFA group compared to 83 and $62 \%$ in the ethanol injection group $(P=0.002)$. There was a trend towards increased overall survival with RFA but this has not yet reached significance (Lencioni et al, 2003). Long-term survival post RFA has also been reported in 206 patients with hepatic cirrhosis and early-stage HCC. The overall survival was $97 \%$ at 1 year, $71 \%$ at 3 years and $48 \%$ at 5 years. Survival of Child-Pugh A patients $(n=144 ; 76 \%$ at 3 years and $51 \%$ at 5 years) was significantly better than that of Child-Pugh B patients $(n=43 ; 46 \%$ at 3 years and $31 \%$ at 5 years, $P=0.0006$ ). A subgroup of 116 patients with Child-Pugh class A cirrhosis and solitary HCC had 3- and 5-year survival rates of 89 and $61 \%$, respectively (Lencioni et al, 2005). These results are sufficiently compelling and it seems likely that RFA will become the treatment of choice for early stage HCC.

\section{PULMONARY NEOPLASIA}

Radiofrequency ablation can be equally well applied to small lung tumours, either primary or secondary. Several hundred treatments have been performed worldwide, a sufficient number to develop a reasonable safety profile (Steinke et al, 2004b). Overall, the complication rate is very similar to that seen following percutaneous lung biopsy. Pneumothorax rates are of the order of $40 \%$, with only $10-15 \%$ requiring drainage or tube insertion. The need for intervention depends on the patient population and underlying lung disease, for example, in our cohort of $>40$ treatments in patients with metastatic pulmonary lesions, it has not yet been necessary to insert an intercostal drain. The pleural effusion rate is similar at $10 \%$. The ideal RFA candidate is a small, peripherally located tumour. Again treatments can be performed under conscious sedation as an overnight or day-case procedure. CT guidance is required and CT fluoroscopy is useful. Successful ablation is denoted by the development of ground glass shadowing that completely encompasses the tumour. Initial consolidation should be larger than the original tumour and then shrink over time such that only a linear scar is visible at 12 months in $33 \%$ of successfully treated tumours (Steinke et al, 2004a). Another useful CT feature, which denotes successful ablation, is the absence of enhancement within the consolidated area. Most centres will treat patients with a limited number of metastases, for example, $<3$ per lung. Again the very focal effects of ablation favour small tumours $<4$ or $4.5 \mathrm{~cm}$. Centrally placed tumours carry the additional risk of collateral damage and the increased likelihood that adjacent cooling blood vessels may protect tumour cells and result in an increased recurrence rate. Currently, RFA is offered to patients with small tumours who are not suitable for conventional treatment. Table 1 summarises the larger series in the literature. Most have concentrated on technical success and complications but Lee et al commented on survival. They reported on ablation of 32 tumours in 30 patients, 26 of whom had primary bronchogenic carcinoma. Complete ablation was achieved in all six tumours less than $3 \mathrm{~cm}$ in diameter and mean survival for this subgroup was 19.7 months vs 8.7 months for the remainder. The use of RFA in conjunction with radiotherapy and/or chemotherapy in the treatment of primary lung cancer is being explored (Jain et al, 2003). New emphasis on screening high-risk populations for the early detection of primary bronchogenic carcinoma will result in the detection of earlier cancers. Not all of these patients will be candidates for surgery, but may be candidates for RFA. As in the liver, RFA is also useful for the treatment of recurrence or new lesions in post surgical patients.

\section{RENAL CELL CARCINOMA}

Nephron sparing techniques such as partial nephrectomy have been shown to be as effective as the traditional total nephrectomy, while providing a reduced morbidity and better preservation of renal function (Lee et al, 2000). Against this background, several groups have explored local ablation techniques in early small renal cell carcinoma and RFA has been very successful. Radiofrequency ablation is usually performed under conscious sedation, with a day-case or overnight stay, using US or CT guidance. Like HCC, the well-defined encapsulated lesions are more amenable to destruction by thermal techniques than ill-defined infiltrating tumours such as hepatic metastases. Most experience has been gained in patients who are not operable candidates or for whom nephron sparing is particularly critical, that is, those who have had previous contralateral nephrectomy, patients with multiple renal cell carcinomas notably those with von Hippel Lindau syndrome. Renal ablation is particularly successful for small, $<4 \mathrm{~cm}$,

Table I Radiofrequency ablation in lung tumours

\begin{tabular}{|c|c|c|c|c|c|}
\hline Authors & $\begin{array}{l}\text { No. of tumours } / \\
\text { patients }\end{array}$ & Histology $1^{\circ} / 2^{\circ}$ & $\begin{array}{l}\text { Tumour size } \\
\text { mean (range) or } \\
\text { maximum cm }\end{array}$ & $\begin{array}{l}\text { Complete ablation - } \\
\text { no. of tumours }\end{array}$ & $\begin{array}{l}\text { Length of } \\
\text { follow-up mean } \\
\text { (range) months }\end{array}$ \\
\hline King et al (2004) & $45 / 20$ & 0/20 (colorectal) & $<3.5$ & $20 / 25(80 \%)$ at 12 months & $24(5-31)$ \\
\hline Lee et al (2004) & $32 / 30$ & $26 / 4$ & $5.2(1-12)$ & $12 / 32(38 \%)$ & $12.5(1-24)$ \\
\hline Yasui et al (2004) & $99 / 35$ & $3 / 96$ & $2.0(0.3-8)$ & $90 / 99(91 \%)$ & $7.1(1-17)$ \\
\hline
\end{tabular}


Table 2 RFA in renal cell carcinoma

\begin{tabular}{|c|c|c|c|c|}
\hline Authors & $\begin{array}{l}\text { No of tumours/ } \\
\text { patients }\end{array}$ & $\begin{array}{l}\text { Tumour size mean } \\
\text { (range) } \mathrm{cm}\end{array}$ & $\begin{array}{c}\text { Complete ablation - } \\
\text { no of tumours }\end{array}$ & $\begin{array}{l}\text { Length of follow-up } \\
\text { mean (range) months }\end{array}$ \\
\hline Schiller et al (2005) & $42 / 34$ & $3.2(1.1-8.9)$ & $36 / 42(86 \%)$ & $9.9(3-43)$ \\
\hline Farrell et al (2003) & $35 / 20$ & $1.7(0.9-3.6)$ & $35 / 35(100 \%)$ & $9(1-23)$ \\
\hline Mayo-Smith et al (2003) & $? / 32$ & $2.4(1-5)$ & $31 / 32(97 \%)$ & $9(1-36)$ \\
\hline Su et al (2003) & $35 / 29$ & $2.2(1-4)$ & $33 / 35(94 \%)$ & $9(0-23)$ \\
\hline
\end{tabular}

exophytic lesions. Central lesions are vulnerable to cooling from adjacent vessels resulting in incomplete ablation. In the largest series published to date, the success rate, that is, complete ablation on immediate contrast enhanced CT was $100 \%$ for exophytic tumours and $45 \%$ for central tumours (Lui et al, 2003). The complication rates are low and the collateral damage to intact nephrons minimised such that renal function remains stable.

Table 2 summarises the main papers published to date.

\section{SYMPTOMATIC PALLIATION}

Occasionally, there is a role for RFA in symptom palliation. Radiofrequency ablation has been successfully applied to bony metastases to relieve pain. Charboneau and co-workers report marked reductions in pain and analgesic requirements following the treatment of limited, localised osteolytic bone metastases (Goetz et al, 2004). One caveat is that there should be a specific, clearly identifiable and localised area of bone destruction responsible for the patients' pain. Radiofrequency ablation has also been used to debulk tumours to reduce pressure symptoms, for example, dyspnoea or dysphagia.

\section{CONCLUSION}

Radiofrequency ablation has proven effective as a local technique for tumour destruction. The complication profile is acceptable. The challenge now is to define in which patient populations and under what circumstances RFA should be used and how best to combine this local technique with systemic therapy.

\section{REFERENCES}

Akeboshi M, Yamakado K, Nakatsuka A, Hataji O, Taguchi O, Takao M, Takeda K (2004) Percutaneous radiofrequency ablation of lung neoplasms: initial therapeutic response. J Vasc Interv Radiol 15: 463-470

Camma C, Schepis F, Orlando A, Albanese M, Shahied L, Trevisani F, Andreone P, Craxi A, Cottone M (2002) Transarterial chemoembolization for unresectable hepatocellular carcinoma: meta-analysis of randomized controlled trials. Radiology 224: 47-54

Elias D, de Baere T, Smayra T, Ouellet JF, Roche A, Lasser P (2002) Percutaneous radiofrequency thermoablation as an alternative to surgery for treatment of liver tumour recurrence after hepatectomy. Br J Surg 89: $752-756$

Farrell MA, Charboneau WJ, DiMarco DS, Chow GK, Zincke H, Callstrom MR, Lewis BD, Lee RA, Reading CC (2003) Imaging-guided radiofrequency ablation of solid renal tumors. AJR Am J Roentgenol 180: $1509-1513$

Gadaleta C, Catino A, Ranieri G, Armenise F, Colucci G, Lorusso V, Cramarossa A, Fiorentini G, Mattioli V (2004) Radiofrequency thermal ablation of 69 lung neoplasms. J Chemother 16(Suppl 5): 86-89

Giacchetti S, Perpoint B, Zidani R, Le Bail N, Faggiuolo R, Focan C, Chollet P, Llory JF, Letourneau Y, Coudert B, Bertheaut-Cvitkovic F, LarregainFournier D, Le Rol A, Walter S, Adam R, Misset JL, Levi F (2000) Phase III multicenter trial of oxaliplatin added to chronomodulated fluorouracil-leucovorin as first line treatment of metastatic colorectal cancer. J Clin Oncol 18: 136-147

Gillams A, Cassoni A, Conway G, Lees W (2005) Radiofrequency ablation of neuroendocrine metastases - the Middlesex experience. Abdom Imaging, http://www.springerlink.com

Gillams AR, Lees WR (2004) Radio-frequency ablation of colorectal liver metastases in 167 patients. Eur Radiol 14: 2261 -2267

Goetz MP, Callstrom MR, Charboneau JW, Farrell MA, Maus TP, Welch TJ, Wong GY, Sloan JA, Novotny PJ, Petersen IA, Beres RA, Regge D, Capanna R, Saker MB, Gronemeyer DH, Gevargez A, Ahrar K, Choti MA, de Baere TJ, Rubin J (2004) Percutaneous image-guided radiofrequency ablation of painful metastases involving bone: a multicenter study. J Clin Oncol 22: 300-306

Jain SK, Dupuy DE, Cardarelli GA, Zheng Z, DiPetrillo TA (2003) Percutaneous radiofrequency ablation of pulmonary malignancies: combined treatment with brachytherapy. AJR Am J Roentgenol 181: $711-715$
King J, Glenn D, Clark W, Zhao J, Steinke K, Clingan P, Morris DL (2004) Percutaneous radiofrequency ablation of pulmonary metastases in patients with colorectal cancer. Br J Surg 91: 217-223

Lee C, Katz J, Shi J, Thaler H, Reuter V, Russo P (2000) Surgical management of renal tumors $4 \mathrm{~cm}$ or less in a contemporary cohort. J Urol 163: $730-736$

Lee JM, Jin GY, Goldberg SN, Lee YC, Chung GH, Han YM, Lee SY, Kim CS (2004) Percutaneous radiofrequency ablation for inoperable non-small cell lung cancer and metastases: preliminary report. Radiology 230: $125-134$

Lees W, Gillams A (2005) Radiofrequency ablation - other abdominal organs. Abdom Imaging, http://www.springerlink.com

Lencioni R, Cioni D, Crocetti L, Franchini C, Pina CD, Lera J, Bartolozzi C (2005) Early-stage hepatocellular carcinoma in patients with cirrhosis: long-term results of percutaneous image-guided radiofrequency ablation. Radiology 228: 235-240

Lencioni RA, Allgaier HP, Cioni D, Olschewski M, Deibert P, Crocetti L, Frings H, Laubenberger J, Zuber I, Blum HE, Bartolozzi C (2003) Small hepatocellular carcinoma in cirrhosis: randomized comparison of radiofrequency thermal ablation $v s$ percutaneous ethanol injection. Radiology 228: $235-240$

Livraghi T, Bolondi L, Buscarini L, Cottone M, Mazziotti A, Morabito A, Torzilli G (1995) No treatment, resection and ethanol injection in hepatocellular carcinoma: a retrospective analysis of survival in 391 patients with cirrhosis. Italian Cooperative HCC Study Group. J Hepatol 22: $522-526$

Livraghi T, Solbiati L, Meloni F, Ierace T, Goldberg SN, Gazelle GS (2003a) Percutaneous radio frequency ablation of liver metastases in potential candidates for resection: the 'test-of-time approach'. Cancer 97: $3027-3035$

Livraghi T, Solbiati L, Meloni MF, Gazelle GS, Halpern EF, Goldberg SN (2003b) Treatment of focal liver tumors with percutaneous radiofrequency ablation: complications encountered in a multicenter study. Radiology 226: $441-451$

Llovet JM, Vilana R, Bru C, Bianchi L, Salmeron JM, Boix L, Ganau S, Sala M, Pages M, Ayuso C, Sole M, Rodes J, Bruix J (2001) Increased risk of tumor seeding after percutaneous radiofrequency ablation for single hepatocellular carcinoma. Hepatology 33: $1124-1129$ 
Lui KW, Gervais DA, Arellano RA, Mueller PR (2003) Radiofrequency ablation of renal cell carcinoma. Clin Radiol 58: 905-913

Mayo-Smith WW, Dupuy DE, Parikh PM, Pezzullo JA, Cronan JJ (2003) Imaging-guided percutaneous radiofrequency ablation of solid renal masses: techniques and outcomes of 38 treatment sessions in 32 consecutive patients. AJR Am J Roentgenol 180: 1503-1508

Ni Y, Mulier S, Miao Y, Michel L, Marchal G (2005) A review of the general aspects of radiofrequency ablation. Abdom Imaging, http://www. springerlink.com

Oshowo A, Gillams A, Harrison E, Lees WR, Taylor I (2003) Comparison of resection and radiofrequency ablation for treatment of solitary colorectal liver metastases. Br J Surg 90: $1240-1243$

Schiller JD, Gervais DA, Mueller PR (2005) Radiofrequency ablation of renal cell carcinoma. Abdom Imaging, http://www.springerlink.com

Solbiati L, Livraghi T, Goldberg SN, Ierace T, Meloni F, Dellanoce M, Cova L, Halpern EF, Gazelle GS (2001) Percutaneous radio-frequency ablation of hepatic metastases from colorectal cancer: long-term results in 117 patients. Radiology 221: 159-166
Steinke K, Glenn D, King J, Clark W, Zhao J, Clingan P, Morris DL (2004a) Percutaneous imaging-guided radiofrequency ablation in patients with colorectal pulmonary metastases: 1-year follow-up. Ann Surg Oncol 11: $207-212$

Steinke K, Sewell PE, Dupuy D, Lencioni R, Helmberger T, Kee ST, Jacob AL, Glenn DW, King J, Morris DL (2004b) Pulmonary radiofrequency ablation - an international study survey. Anticancer Res 24: 339-343

Su LM, Jarrett TW, Chan DY, Kavoussi LR, Solomon SB (2003) Percutaneous computed tomography-guided radiofrequency ablation of renal masses in high surgical risk patients: preliminary results. Urology 61: $26-33$

Vogl TJ, Straub R, Eichler K, Sollner O, Mack MG (2004) Colorectal carcinoma metastases in liver: laser-induced interstitial thermotherapy local tumor control rate and survival data. Radiology 230: 450-458

Yasui K, Kanazawa S, Sano Y, Fujiwara T, Kagawa S, Mimura H, Dendo S, Mukai T, Fujiwara H, Iguchi T, Hyodo T, Shimizu N, Tanaka N, Hiraki Y (2004) Thoracic tumors treated with CT-guided radiofrequency ablation: initial experience. Radiology 231: 850-857 